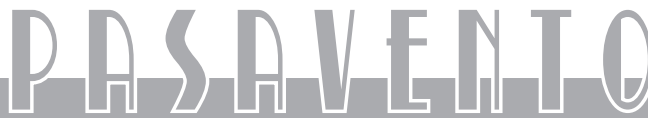

Revista de Estudios Hispánicos

Vol. I, n. ${ }^{\circ} 1$ (invierno 2013), pp. 153-162, ISSN: 2255-4505

\section{CARTOGRAFÍAS DE LA H(H)ISTORIA. ENTREVISTA A IGNACIO MARTÍNEZ DE PISÓN}

Carmen Valcárcel

Universidad Autónoma de Madrid

Carmen Valcárcel. "Las cosas casi nunca son como aparentan [...] vemos solo una pequeña parte y creemos que lo estamos viendo todo, cuando lo más importante permanece oculto, sumergido". Estas palabras de María, la joven protagonista de María bonita, podrían ser el hilo conductor para adentrarnos en el mundo literario de Ignacio Martínez de Pisón (Zaragoza, 1960). Ya desde sus primeros libros, la novela La ternura del dragón (1984), la colección de cuentos Alguien te observa en secreto (1985) y las dos novelas cortas Antofagasta y La última isla desierta (1987), el escritor parte de un marco realista para introducir un elemento inquietante y perturbador. Esa perspectiva a contraluz ilumina y oscurece, al mismo tiempo, la narración y modifica el molde realista en que se inserta, al conducir al lector hacia las zonas misteriosas, las sombras, los espejismos; bucear en los fantasmas de la infancia, los secretos, los fingimientos. ¿El realismo abarca, como parece al menos en tus obras iniciales, no solo elementos reconocibles sino también inquietantes, enigmáticos? ¿Es ese "realismo insólito" o " extraño" en tus inicios un impuesto de época?

Ignacio Martínez de Pisón. En realidad, yo no hablaría de "realismo". Lo último que entonces querría ser un escritor joven era un escritor realista. Y las opciones que en ese momento nos ofrecía la corriente más fresca en lengua española, el llamado boom latinoamericano, tampoco eran tantas. Descartado el realismo mágico, que en una sociedad como la nuestra habría sido una simple impostura, nos quedaba la literatura de corte más fantástico. Eso sí, los elementos fantásticos tendían a surgir de la propia cotidianidad. 
CV. Empezaste a publicar muy joven, a los veinticuatro años. Ese hecho revela y desvela, de alguna manera, los años de tu aprendizaje como escritor. Has afirmado, con humor, que sería muy triste pasar a la historia de la literatura española de las últimas décadas por Nuevo plano de la ciudad secreta (1992), y sin embargo esas primeras obras son los andamiajes sobre los que se ha ido levantando tu obra literaria. Es cierto que esta adquiere mayor vuelo, mayor envergadura, posiblemente a partir de Carreteras secundarias (1996), pero ¿no es interesante también acercarse a los textos anteriores para ver cómo se ha ido preparando ese despegue?

IMP. Esos primeros libros constituyen la prehistoria del escritor que he sido después. Algunas cosas estaban ya ahí. Otras, en cambio, las he ido rectificando con el tiempo hasta llegar en algunas ocasiones a negarlas por completo. El caso de Nuevo plano de la ciudad secreta es peculiar, porque hay varias partes de esa novela que me gustan y en las que todavía me reconozco, pero considero fallido el resultado final. De hecho, es un libro que he suprimido de mi bibliografía. Bueno, lo he hecho de la única manera que un escritor puede hacerlo: no permitiendo que se reedite.

CV. A partir de la ya citada Carreteras secundarias (1996), la realidad que aparece en tus obras adquiere contornos más identificables. En esta, igual que en María bonita (2001), El tiempo de las mujeres (2003), Dientes de leche (2008) o El día de mañana (2011), ofreces una narración enmarcada en un fondo histórico, pero sin servidumbres historicistas, sin pretensiones cronísticas. A pesar de ello, en esas historias ficticias podemos percibir los ecos de la Historia con mayúscula, en la medida en que reflejan el espíritu de una época: la España desde finales de la dictadura franquista a los años 90. Un tiempo histórico que es, a su vez, un tiempo biográfico: el tiempo de tu infancia, adolescencia y juventud. ¿Cómo barajas en tu obra la memoria colectiva y la memoria personal?

IMP. Todos somos producto de una sociedad y una época determinadas, y los grandes acontecimientos de nuestra historia colectiva no pueden sernos ajenos, menos aún para un novelista. La gran tradición realista siempre lo ha tenido muy claro, y a través de la peripecia de sus mejores personajes podemos atisbar cómo fue el momento histórico que le tocó vivir al autor. Pero digamos que también aquí las pinceladas son más eficaces que los brochazos: nada estorba tanto como esos pedazos de crónica histórica en bruto que a veces los novelistas incrustan en sus narraciones.

CV. En el proceso de reconstrucción e identificación de esa época, te sirves tanto de referentes históricos concretos como de detalles culturales y generacionales (marcas de coches, revistas de época, personajes famosos, películas, canciones...) que nos acercan a un tiempo vivido y sentido como testigo. ¿Qué importancia tienen en tu obra esos detalles que van definiendo la vida de los personajes al mismo tiempo que la del país? 
IMP. Nabokov decía que el novelista tenía que estar muy atento a los detalles. Estos no deben ser meros elementos de atrezzo. Tienen que contribuir de algún modo a esa verdad que el novelista aspira a transmitir en su historia. Supongo que con una novela ambientada en la Edad Media podríamos tomarnos más libertades. Con una novela ambientada en una época que muchos lectores han podido conocer la cosa cambia. Esos detalles, digamos de época, ayudan a enmarcar la acción en el contexto apropiado y aportan algo de ese aroma de autenticidad que las novelas necesitan. Nombrar, por ejemplo, un modelo determinado de coche tiene unas implicaciones muy superiores a emplear simplemente la palabra coche: nos habla de la época pero también del personaje, de cómo cree que es o cómo se ve a sí mismo. En eso soy también como los novelistas norteamericanos: del mismo modo que te dicen el nombre de una calle desconocida de una población desconocida, te dicen también qué modelos de coche utiliza el protagonista.

CV. También es perceptible cómo las referencias espaciales han ido introduciéndose paulatinamente en tu narrativa, perfilando un mundo mucho más concreto. Desde la ausencia absoluta de topografía explícita en La ternura del dragón, desde su presencia difuminada e indirecta en Carreteras secundarias, llegamos a El día de mañana, que es una novela sobre Barcelona, en la que la fisonomía de la ciudad y la fisonomía de los personajes terminan (con)fundiéndose. Y junto a Barcelona, sin duda Zaragoza, ciudad protagonista de algunos de tus cuentos y novelas (El tiempo de las mujeres, Dientes de leche). Zaragoza aparece como el "espacio de los recuerdos", de la infancia y de la juventud. Alli naciste, estudiaste con los jesuitas y te licenciaste en Filología Hispánica. Pero también es un "espacio literario", tan complejo y fascinante como puede ser París o Nueva York. Por otro lado, aunque las historias que narras se ubican en un tiempo y un espacio determinados, hay un cierto afán por trascender esos límites y otorgar carácter universal a los conflictos que mueven a los personajes: la vida familiar, las relaciones de pareja, el abuso del poder, la traición, el desencanto, la soledad... ¿Cuáles son los mecanismos de tu narrativa para ampliar o trascender esa realidad concreta de la que parten muchas de tus obras?

IMP. Algo tuvo que ver en ello el descubrimiento de la mejor literatura norteamericana, que jamás nos hurta el nombre de una calle o una población, por insignificantes y desconocidas que sean. Y en el caso de la aparición de Zaragoza como espacio de los recuerdos no puedo negar la influencia de un gran escritor zaragozano como es José María Conget, varios de cuyos libros están construidos precisamente sobre los recuerdos de esa Zaragoza que abandonó nada más acabar la carrera. Conget es unos cuantos años mayor que yo, pero su Zaragoza es casi contemporánea a la mía. Descubrirla en sus libros me enseñó que los lugares prestigiosos no hacen mejores las novelas.

CV. La realidad que aparece en tus obras ofrece siempre un lado ominoso y extraño, una "Zona Deshabitada", un mundo en penumbra. Hay mayor interés por abordar 
los márgenes de esa realidad, sus espacios clandestinos. Por ejemplo, escribir una novela sobre los fascistas italianos que estuvieron en España como voluntarios durante la Guerra Civil en Dientes de leche, sobre el funcionamiento de la Brigada Político-Social durante el franquismo en El día de mañana o la novela que escribes ahora sobre los judios del protectorado. Ese desplazamiento focal hacia las esquinas o la penumbra del mundo real obliga a indagar más allá de la superficie de los hechos narrados y otorga una nueva dimensión a la (H)historia. ¿Qué te induce a adoptar tal enfoque: romper con clichés y repeticiones manidas, cuestionar la opinión dominante, contar los acontecimientos históricos de otra manera?

IMP. El riesgo de caer en el cliché es, en efecto, el primero que el escritor debe evitar. Y nada mejor para eso que enfrentarse a temas sobre los que no hay nada o hay muy poco escrito. El tema de los fascistas italianos en España me interesaba especialmente por lo que tiene de utopía monstruosa que, sin embargo, fue capaz de seducir a mucha gente, y no solo a gente sin formación sino también a gente cultivada y valiosa. Que el fascismo hubiera sido derrotado en Italia pero pudiera seguir gozando del prestigio y los privilegios de los vencedores en España, una de las últimas dictaduras europeas, lo hacía aún más interesante. A través del personaje central podía, además, hablar del autoritarismo que presidió la vida de la España en la que crecí, un autoritarismo que lo impregnaba todo.

CV. Desde 1984 has escrito más de una docena de obras narrativas, entre novelas, novelas cortas y cuentos. ¿Cómo te planteas la escritura de un libro de cuentos, una novela corta o nouvelle y una novela de dimensiones más canónicas? ¿Hay trasvases de un género a otro?

IMP. Últimamente, casi no escribo cuentos. Cuando me pongo a trabajar en una novela, es como si estuviera conviviendo con los personajes, y no me resulta fácil abandonarlos por una temporada para escribir un texto breve que nada tiene que ver con ellos. Pero es verdad que durante años alterné la escritura de relatos y la de novelas. Supongo que todo dependía de la idea. En cuanto tenía una idea, tenía también una intuición bastante precisa de si podía desarrollarse como cuento o como novela.

CV. Cada una de tus obras, ha supuesto un nuevo reto frente a la anterior, sin perder nunca tu voz como escritor, que empieza a definirse, como tú mismo has reconocido, a partir de Carreteras secundarias. Cada una plantea una nueva revisión tanto temática como de procedimientos ficcionales. Uno de esos desafíos, para alguien que es esencialmente novelista, supongo que fue Enterrar a los muertos (2005) o, en esa misma línea, aunque sean reportajes o "relatos reales", los siete textos de Las palabras justas (2007). ¿Es posible, sin ser historiador, ceñirse a la realidad histórica; es posible, siendo escritor, preservar esa realidad de la imaginación? 
IMP. Para mí, la experiencia de escribir Enterrar a los muertos fue una revelación. Me descubrió, sobre todo, que mi imaginación nunca será tan fecunda como la realidad. Esta no solo es, como decía Woody Allen, el sitio donde puedes encontrar un buen chuletón de ternera. La realidad está llena de historias apasionantes que están esperando a la persona que quiera contarlas. Desde aquel libro me acostumbré a buscar historias en esa inmensa despensa que es la realidad.

CV. ¿Cuál es el proceso de documentación en un caso y en otro? Es decir, ¿cómo maneja el novelista la Historia a la hora de escribir una obra ficticia, con un marco histórico como telón de fondo, y a la hora de escribir un ensayo histórico?

IMP. Tradicionalmente, los historiadores centraban su atención en los grandes acontecimientos, los grandes protagonistas de la Historia, los grandes movimientos de masas... Las pequeñas historias individuales parecían no interesarles. Hace ya tiempo que estas han empezado a interesar a unos cuantos, y curiosamente este fenómeno ha coincidido con cierta "literaturización" de los estudios historiográficos. Uno de los mejores ejemplos es Carlo Ginzburg, no por casualidad hijo de la gran novelista Natalia Ginzburg. En él se combinan perfectamente el rigor del buen investigador de la Historia con el buen uso de los recursos narrativos. Las fronteras entre literatura e Historia se confunden. Enterrar a los muertos es un libro que se mueve en esa zona intermedia.

CV. Durante algunos años trabajaste como crítico en el ABC Cultural y en El País. ¿Cómo recuerdas esa etapa? ¿Qué te aportó esta experiencia para escribir?

IMP. Fue, sobre todo, un excelente aprendizaje. Lo mismo podría decir de mi experiencia como traductor. Si esta me obligaba a enfrentarme a una historia ajena como si yo fuera el autor de esa novela, aquella me obligaba a desentrañar las claves ocultas de un libro para exponérselas a un lector desconocido. Esos dos acercamientos a la literatura desde puntos de vista diferentes me resultó muy enriquecedor. En el caso de la crítica literaria, lo más útil era enfrentarme a un libro que no me gustaba y tener que preguntarme por qué ese libro no me gustaba. De los errores ajenos puede uno llegar a aprender tanto como de los propios.

CV. Esa mirada del crítico, una manera especial de leer, entender y valorar la obra literaria, se materializa en uno de tus libros más interesantes, Partes de guerra (2009). El volumen puede abordarse como una antología de treinta y cinco cuentos sobre la Guerra Civil tanto de autores que vivieron el conflicto bélico (Max Aub, Arturo Barea, Juan Eduardo Zúñiga) como de autores de generaciones posteriores (Ignacio Aldecoa, Fernando Quiñones, Andrés Trapiello), de escritores de ideologías opuestas (Ramón J. Sender / Rafael García Serrano; María Teresa León / Edgard Neville) o de escritores de otras lenguas peninsulares (Pere Calders, Manuel Rivas o Bernardo Atxaga). Sin embargo, como tú mismo explicas en el "Prólogo", no has querido "reunir un ramillete de buenos relatos sino 'contar' la guerra civil". Ofreces 
así una suerte de itinerario del conflicto bélico, ordenando cronológicamente los textos: desde poco antes del 18 de julio de 1936 ("La lengua de las mariposas" de Rivas) hasta poco después del 1 de abril de 1939 ("Campo de los almendros" de Jorge Campos), a la vez que propones al lector un puzle colectivo sobre la guerra a partir de ese conjunto de cuentos. ¿Cómo surgió este proyecto? ¿Cómo se integra en el proyecto más amplio de tu escritura?

IMP. Salió todo un poco por casualidad. A veces las mejores ideas surgen en una conversación de bar. Eso fue lo que ocurrió con este libro. Estaba con mi amigo Malcolm Otero Barral, que entonces trabajaba en la editorial RBA, y le hablé de unas reflexiones de Italo Calvino sobre los relatos de la resistencia antifascista italiana. De ahí a pensar que algo parecido podía llevarse a cabo con relatos sobre la Guerra Civil española solo había un paso. Me puse a buscar cuentos un poco por curiosidad y acabé descubriendo que había auténticas joyas, muchas de ellas desconocidas para el lector contemporáneo. Esto ocurría en la época en que más me interesaba la Guerra Civil, así que para mí fue una actividad muy placentera: nada mejor que leer literatura sobre un asunto que te apasiona $y$, además, que te paguen por ello.

CV. En El tiempo de las mujeres (2003) ya habías adoptado esa perspectiva poliédrica para aprehender la realidad, a partir de las voces en primera persona de las tres jóvenes protagonistas, María, Carlota y Paloma. El derrumbe de sus vidas, tras la muerte del padre, las enfrenta a un nuevo mundo, un mundo que cada una de ellas ha de construir; su itinerario personal se une, de manera simbólica, al proceso de construcción colectiva tras la muerte de Franco. La narración, ambientada en Zaragoza, conjuga tres tiempos: el pasado, representado por la madre; el presente, en el que el sentimiento inicial de desamparo se pliega al de independencia, y el futuro que cada una de ellas -como mujeres en la España de esa época- irá trazando. Creo que es una novela que evidencia la fragilidad de los cimientos sobre los que se construye nuestra existencia y sobre la vulnerabilidad de la sociedad española de esos años.

IMP. Es una novela construida sobre la certidumbre de que algo muy importante estaba cambiando: al margen de los cambios estrictamente políticos, eran los años en los que se estaba definiendo el nuevo papel de la mujer en la sociedad. Ese contraste tan marcado entre la generación de las madres y la de las hijas ni se había registrado antes ni volverá a darse nunca más. Y para un novelista nada hay más jugoso que esos contrastes.

CV. Vuelves a utilizar esa perspectiva caleidoscópica en El día de mañana, donde la autoría narrativa se diluye en múltiples voces, logrando el máximo perspectivismo. El lector reconstruye el personaje de Justo Gil a través de las piezas que cada uno de los narradores le va ofreciendo, al tiempo que reconstruye la vida del resto de los personajes. Novela coral y contrapuntística, en la que se conoce y a la vez paradójicamente se desconoce al protagonista, ya que, por un lado, se ofrece al 
lector la posibilidad de recomponer al personaje de Justo, eje central de la narración, pero, al mismo tiempo, se le niega esa posibilidad, en la medida en que solo podemos conocerle a través de la historia de los otros, de los demás. La novela se erige a partir de una realidad fragmentada en la que la verdad no se alcanza con la suma de las múltiples visiones subjetivas; en todo caso, si fuera posible llegar a esa "verdad" sería a través de la pugna entre cada una de esas imágenes. Me parece que, además de un relato ficticio sobre un delator de la policía y sobre la España de los años 60 y 70, El día de mañana es una novela sobre la identidad, sobre la complejidad de la identidad humana.

IMP. Me parecía imprescindible que no oyéramos la voz de Justo Gil y que, en cambio, oyéramos a quienes lo conocieron hablando de él. Lo que cada uno de nosotros pueda decir de sí mismo seguramente nos reflejará con menos acierto que lo que puedan decir de nosotros quienes nos han tratado a lo largo del tiempo. Además, se da la circunstancia de que Justo Gil se dedica a lo que se dedica, a dar chivatazos a la policía política del franquismo, lo que facilitaba las cosas: se trataba sobre todo de contar la historia de un personaje opaco por naturaleza.

CV. ¿Desde un punto de vista técnico, qué ventajas te ha proporcionado el uso de esta perspectiva múltiple frente a otras estrategias, como el narrador en primera persona o el narrador focalizado en un solo personaje?

IMP. La alternancia de puntos de vista da mucho juego al novelista. Lo que dice un narrador puede inmediatamente ser desmentido o ampliado o puntualizado por otro. En ese juego de verdades acaba expresándose la esencia relativista del propio género: la novela, por naturaleza, huye de las verdades absolutas e inamovibles.

CV. Los personajes de tus obras suelen ser antihéroes, individuos desorientados, incapaces de tomar las riendas de su vida, estafadores, perdedores, ilusos, delatores, locos... Pero hay hacia ellos una mirada tierna, piadosa; prevalece un propósito de comprensión humana, de acercamiento a la conciencia y a los sentimientos de esos seres abocados al fracaso o al drama. ¿Por qué tus protagonistas comparten estos rasgos? ¿Qué es lo que los hace interesantes?

IMP. Casi ninguno de mis personajes es admirable, y el que lo es lo es por motivos menores y de una forma casi clandestina. Me interesan poco los grandes personajes y mucho las criaturas menores, casi anónimas. Y todos tienen el mismo derecho a la piedad. Como novelista, me siento obligado a buscar explicación a todo tipo de comportamientos, incluidos los más abominables. A estos últimos no les busco justificación, pero creo que tampoco les puedo negar el derecho a que alguien trate de explicarlos, a que alguien intente averiguar por qué han acabado haciendo esas cosas abominables. Entender, por ejemplo, a un 
fascista como el de Dientes de leche o a un chivato como el de El día de mañana no implica comprenderlo ni mucho menos exculparlo.

CV. Has colaborado en varios proyectos cinematográficos. En el guion de Carreteras secundarias (1997) para la película de Emilio Martínez Lázaro, basada en tu novela homónima; en el de Las trece rosas (2007) de nuevo con Martínez Lázaro, a partir del libro de Carlos Fonseca, y, recientemente, junto con Fernando Trueba, en el de Chico \& Rita (2010), dirigida por el mismo Trueba, Javier Mariscal y Tono Errando. Siendo dos lenguajes distintos y utilizando medios diferentes, ¿en qué medida literatura y cine comparten un mismo fin?

IMP. La esencia última no es tan diferente. Se trata, en definitiva, de contar de la mejor manera posible una buena historia. Y aunque cambien los lenguajes, ese afán por contar es común al guionista y al novelista que, como yo, se considera por encima de todo un narrador.

CV. ¿Cómo te enfrentaste a tres colaboraciones cinematográficas distintas: la adaptación de una obra tuya (Carreteras secundarias), la adaptación de la obra de otro autor (Las trece rosas) y la escritura de un guion original (Chico \& Rita)?

IMP. En realidad, el único argumento propio era el de Carreteras secundarias. El de Las trece rosas lo hice mío porque el libro de Fonseca, que buscaba sobre todo documentar la tragedia de esas chicas, no tenía una estructura aprovechable para un guion, así que tuve que reinventar a las protagonistas. El de Chico \& Rita es un caso distinto porque trabajaba sobre un argumento en el que yo no había intervenido. De los tres guiones, es el que considero menos "mío".

CV. Algunos de tus libros han sido ilustrados: Alberto Torro ilustra La ley de la gravedad (Zaragoza, Ediciones del Valle, 1987) y José Luis Cano, El filo de unos ojos (Zaragoza, Diputación General de Aragón, 1991); o bien incorporan fotografías con valor documental: Las palabras justas o Enterrar a los muertos. ¿Qué aporta esa conjunción de miradas al texto?

IMP. En el caso de estos dos últimos libros, las imágenes eran algo así como un certificado de veracidad. Quería que el lector tuviera siempre presente que estaba leyendo una "historia real", con unos protagonistas que tenían una vida, una familia, un aspecto determinados. Quería, además, que las ilustraciones estuvieran incorporadas al texto de forma que, más que ilustrarlo, lo completaran. En alguna traducción extranjera de Enterrar a los muertos he visto que han puesto las ilustraciones en láminas aparte, y me parece que la lectura de ese libro será distinta y probablemente más pobre.

CV. En 1990 se estrenó, en la Sala Margarita Xirgu del Teatro María Guerrero, la adaptación teatral de tu cuento "El filo de unos ojos", publicado en Alguien te observa en secreto. El texto narra una relación de poder, en el seno además familiar: 
la que ejerce el primo del protagonista sobre este (Fernando y Diego respectivamente en la versión dramática). ¿Por qué elegiste un cuento sobre la "dominación" y la "humillación"? ¿Cómo afecta el ámbito de la representación teatral, como espacio para la transfiguración, el camuflaje y la mentira, a la interpretación del cuento?: ¿quién domina y quién se deja dominar?, ¿quién actúa y quién mira?, ¿actuamos para los demás? ¿actúan los demás para nosotros?

IMP. El relato en el que está basada esa pequeña obra teatral buscaba, en efecto, explorar las relaciones de poder que se establecen entre las personas. No fui yo quien eligió llevarlo al teatro. Fue más bien una invitación, un encargo. Pero creo que la historia tiene un componente esencialmente teatral. Los dos personajes actúan y ven actuar. Son siempre conscientes de que tienen un público, que es a la vez su antagonista. Llevar el cuento al teatro consistía sobre todo en aprovechar esa faceta digamos escénica: personas que hacen algo delante de alguien con la finalidad de que se vea lo que hacen.

CV. Asimismo, has escrito tres novelas juveniles, El tesoro de los hermanos Bravo (1996), El viaje americano (1998) y Una guerra africana (2000). En ellas aparece uno de los temas medulares de tu narrativa: cómo se incorpora el niño al mundo de los adultos. Quizá no haya tanta diferencia entre algunas de tus novelas "para adultos" y tus novelas "para jóvenes". En estas se aborda de nuevo ese paso de la infancia a la madurez, el abandono de un ámbito protector para pasar a un mundo desconocido. En ese proceso de aprendizaje confluyen fantasías, deseos, odios, desencanto y en no pocas ocasiones soledad y dolor; temas que ya habían acompañado a los jóvenes protagonistas de La ternura del dragón, Carreteras secundarias, María bonita o El tiempo de las mujeres. ¿Qué otras similitudes habría entre tu obra para jóvenes y tu obra para adultos? ¿Cómo enfrentas la escritura de estos textos? ¿Se trata de encargos o los has concebido a iniciativa tuya?

IMP. No fueron encargos sino proyectos literarios que concebí un poco al modo de pasatiempos. El viaje americano y Una guerra africana debían formar parte de un ciclo más amplio que iba a tener a José Carril como protagonista principal. La idea era llevarlo por algunos escenarios interesantes de los años veinte y treinta (y quizás cuarenta) de forma que, al mismo tiempo que siguiéramos sus aventuras, fuéramos testigos de algunos de los hechos históricos decisivos de aquella época tan convulsa. Pero un proyecto así exige mucho esfuerzo y mucha constancia, y no sé si algún día lo retomaré. De momento, solo están esos dos "episodios internacionales", el de la guerra del Rif y el del nacimiento del cine sonoro en Hollywood. Entre tanto asistimos también a la formación del personaje central. En definitiva, todo el proyecto pretendía ser algo así como una larga novela de formación. También hay algo de eso en Los hermanos Bravo, que muestra el despertar a la vida y al amor y a la literatura de un adolescente de esa España del interior a la que el progreso ha acabado dando la espalda. Y, desde luego, no se puede negar que esos libros estén emparentados con otras novelas mías. La literatura (no solo la mía) tiende a fijarse en aquellos acontecimientos 
que modifican a las personas. Cuando uno es un niño o un adolescente, esos acontecimientos abundan. De ahí que me interesen tanto esos protagonistas a los que el lector ve haciéndose a lo largo del relato.

CV. En Zaragoza te licenciaste en Filología Hispánica y en Barcelona en Filología Italiana. También te has dedicado a la traducción. Un desafío más en tu proteica obra literaria. ¿A qué autores has traducido? ¿Hay una elección consciente por parte del traductor del escritor y obra que va a traducir? ¿Un reflejo especular quizá, una identificación creadora?

IMP. Traduje varias novelas italianas (de Daniele del Giudice, de Guido Morselli...) en los años ochenta, cuando todavía publicaba mis novelas en Anagrama. En aquella época había un interés por la literatura italiana contemporánea que luego se ha ido diluyendo. Yo no elegía los libros sino que traducía los que el editor, Jorge Herralde, me proponía. Fue, como ya he dicho, un excelente aprendizaje. Y seguramente habría seguido traduciendo si con ellos hubiera podido ganarme bien la vida. Pero ya se sabe que, por desgracia, la traducción en España es una profesión muy poco valorada.

CV. Este año has ganado el Premio de la Crítica y antes obtuviste el Premio Casino de Mieres por La ternura del dragón, el Torrente Ballester por Nuevo plano de la ciudad secreta, el Premio NH 1999 por Foto de familia, el Pedro Saputo 2000 por María bonita, el Dulce Chacón de Narrativa Española por Enterrar a los muertos, el Premio San Clemente 2009 por Dientes de leche, el Premio de las Letras Aragonesas 2011 o el Premio Ciutat de Barcelona 2012 por El día de mañana, entre muchos otros. ¿Cómo vive un escritor esos reconocimientos?

IMP. Los primeros dos premios que gané eran premios a los que tenías que presentarte. Me parece que ese tipo de premios están bien precisamente para que los autores jóvenes asomen la cabeza en el mundo editorial. Luego, cuando dejé de ser un escritor joven, dejé también de presentarme a premios, y los otros que he recibido han sido reconocimientos a libros ya publicados. El escritor trabaja en soledad y pocas veces es consciente de la recepción de su trabajo. Esos premios te ayudan a pensar que lo que haces es importante para alguien, cosa que siempre anima a seguir escribiendo. Se diga lo que se diga, el escritor no es nadie sin lectores. 